\title{
Apontamentos sobre pesquisa qualitativa e pesquisa empírico-fenomenológica'
}

\author{
Notes on qualitative research and empirical \\ phenomenological research
}

\author{
Celana Cardoso ANDRADE ${ }^{2}$ \\ Adriano Furtado HOLANDA ${ }^{3}$
}

\begin{abstract}
Resumo
Este estudo visa apresentar, numa perspectiva teórica, a pesquisa qualitativa e o método fenomenológico, tomando por base o modelo empírico-compreensivo de Amedeo Giorgi. Na busca por minimizar as dificuldades encontradas na aplicação do método fenomenológico, no que concerne à grande variedade de interpretações, e explicitar como se constituem os resultados dessa prática de pesquisa, foi necessário esclarecer a natureza qualitativa da realidade investigada, o modelo de relação entre investigador-investigado e o modo como se obtiveram o conhecimento do problema e os aspectos intrinsecamente relacionados. Com o intuito de abranger esse conteúdo, o artigo dividiu-se em três partes. Foi feita, inicialmente, uma introdução sobre a pesquisa qualitativa; posteriormente, propôs-se discutir a fenomenologia e seus principais conceitos, e, na terceira parte deste artigo, foi estudado o método fenomenológico, em especial o modelo desenvolvido por Giorgi.
\end{abstract}

Unitermos: Fenomenologia. Métodos empíricos. Pesquisa qualitativa.

\begin{abstract}
This study addressed, from a theoretical perspective, qualitative research and the phenomenological method based on the empiricalcomprehensive model of Amedeo Giorgi. In an effort to minimize the difficulties found when applying the phenomenological method, in terms of the great variety of interpretations and also in explaining the manner in which the results of this kind of research are constituted, it was necessary to clarify the qualitative nature of the situation under investigation, the investigator/investigatee relationship model and the way in which an awareness of the problem has been created, as well as the related, intrinsic aspects. With the aim of embracing all this content, this paper was divided into three parts. Firstly, an introduction into qualitative research was carried out. The second part proposed a discussion on Phenomenology and its main concepts and, in the third part of this paper, with regard to qualitative research, the phenomenological method was studied, in particular the model developed by Giorgi.
\end{abstract}

Uniterms: Phenomenology. Empirical methods. Qualitative research.

1 Artigo elaborado a partir da dissertação de C.C. ANDRADE, intitulada "A vivência do cliente no processo psicoterapêutico: um estudo fenomenológico na Gestalt-Terapia". Universidade Católica de Goiás, 2007.

2 Universidade Federal de Goiás, Faculdade de Educação, Departamento de Psicologia. R. 1138, 212, Setor Marista, 74180-170, Goiânia, GO, Brasil. Correspondência para/Correspondence to: C.C. ANDRADE. E-mail: <celana@terra.com.br>.

3 Universidade Federal do Paraná, Departamento de Psicologia. Paraná, PR, Brasil. 
O final da década de 1970 foi marcado por uma ampla discussão dos limites e possibilidades das diferentes posições assumidas ante o conhecimento psicológico. A emergência de novos problemas em sua construção e a ostensiva perda da influência do paradigma positivista contribuíram para uma reflexão crescente do processo de construção do conhecimento em psicologia. Propôs-se, então, a epistemologia qualitativa: uma teoria que busca a produção do conhecimento e a inteligibilidade do real (González Rey, 2003).

A proposta deste artigo é apresentar uma discussão sobre o sentido da pesquisa qualitativa a partir do olhar fenomenológico. Com o intuito de abarcar esse conteúdo, o artigo divide-se em três partes: uma introdução sobre a pesquisa qualitativa, que defende uma compreensão particular e, ao mesmo tempo, complexa do fenômeno estudado; uma discussão sobre a fenomenologia e seus principais conceitos numa perspectiva de entrelaçamento com a pesquisa qualitativa; e uma discussão sobre o método fenomenológico, tomando por base uma análise do modelo empírico-compreensivo proposto por Amedeo Giorgi.

\section{$O$ contexto epistêmico da pesquisa qualitativa}

Holanda (2002) assinala que a pesquisa qualitativa constituiu um significativo avanço para as ciências humanas e preencheu espaços que o modelo quantitativo não alcançava: "o espaço da interlocução com o humano, o espaço de busca dos significados que estão subjacentes ao dado objetivo, o espaço de reconstrução de uma ideia mais abrangente do que é empírico, um espaço de construção de novos paradigmas para as ciências humanas e sociais" (p.156).

Os lugares ocupados pela pesquisa qualitativa permitem a busca da subjetividade, que se apresenta como um conjunto de processos "os quais mudam em face do contexto em que se expressa o sujeito concreto" (González Rey, 2002, p. 51).

O trabalho com questões complexas não permite ao pesquisador uma definição exata e a priori dos caminhos da pesquisa. A flexibilidade no processo de condução é uma das características da pesquisa qualitativa. González Rey (2005) enfatiza:"tomar o novo como que tem de novidade" (p.18). Assim, o percurso da pesquisa depende do contexto em que está inserida, sem esquecer que o pesquisador exerce influência sobre a situação da pesquisa e é por ela também influenciado.

Essa complexidade também é marcada pela mútua influência entre pesquisador e pesquisado, pois ambos produzem pensamentos com base na sua posição diante do outro e de si mesmo, o que influencia o processo da pesquisa. Buber $(1965 ; 1979 ; 1982)$ sustenta a ideia da influência mútua ao destacar, em grande parte de sua obra, que o humano se estabelece na relação ou, conforme sua própria terminologia, na esfera do inter-humano. Esse posicionamento corrobora as características da pesquisa qualitativa, em que se destaca a parceria pesquisador-pesquisado: uma singularidade que influencia o outro em um contexto específico.

Diante da participação ativa do pesquisador - característica da pesquisa qualitativa -, sua história e seu contexto cultural devem ser entendidos como elementos de grande significado na pesquisa, pois "marcam uma singularidade que é a expressão da riqueza e plasticidade do fenômeno subjetivo" (González Rey, 2002).

Outra característica fundamental da pesquisa qualitativa é, segundo Martins e Bicudo (2005), o fato de que a pesquisa qualitativa busca uma compreensão particular daquilo que estuda, já que o foco de sua atenção é dirigido para o específico, o individual, aspirando à compreensão dos fenômenos estudados que somente surgem quando situados.

Ao destacar essas características da pesquisa qualitativa, observa-se que são qualidades comuns a outros modelos de pesquisa em ciências humanas. Moustakas (1994) destaca o foco na experiência de totalidade, a busca de significados e essências da experiência - alcançados com base nas descrições da experiência singular do sujeito pesquisado - e o comprometimento do pesquisador e do pesquisado na expectativa de atingir a totalidade do fenômeno.

Nas várias modalidades de pesquisa qualitativa, pesquisador e sujeito são produtores de pensamento. A especificidade desse tipo de pesquisa refere-se à busca dos aspectos da realidade do sujeito, considerando que esses aspectos são apreendidos por sujeitos pesquisadores.

Essas características estão explicitadas nas considerações de González Rey (2002; 2005), que adverte que 
o pesquisador deve estar aberto a mudar suas próprias ideias para facilitar a produção de conhecimentos, visto que a produção de teorias é um processo essencialmente qualitativo, pois o momento da pesquisa é considerado um momento de confrontação e desenvolvimento de novas teorias. Isso é corroborado pela literatura que aponta a pesquisa qualitativa como voltada para a descoberta e para a constituição de novos espaços de leitura de fenômenos da realidade (Bruns \& Holanda, 2003; Gomes, 1998, Holanda, 2002; 2006; Martins \& Bicudo, 2005).

A pesquisa busca manter uma relação constante entre quatro diretrizes: a teoria, o momento empírico, os instrumentos e o processo de construção e interpretação de informações com a produção de conhecimentos, em um desenvolvimento contínuo, estabelecido tanto pelo pesquisador como pelo pesquisado. Assim, a pesquisa qualitativa não corresponde somente a uma definição instrumental, ela é epistemológica e teórica e apoia-se em processos singulares de construção de conhecimento. O pesquisador que, em geral, focaliza simplesmente a diferença metodológica, distingue o qualitativo e o quantitativo somente no plano das técnicas (Amatuzzi, 1996; Bruns \& Holanda, 2003; González Rey, 2002; Holanda, 2002; 2003a; 2006).

Ao buscar uma informação singular, o pesquisador retira a teoria de foco, aceitando o empírico como via de produção do conhecimento e possibilidade de construção de novas teorias, sobretudo em razão de a teoria representar um processo vivo em desenvolvimento e construção (Amatuzzi, 1996; 2003; Gomes, 1998; Holanda, 2002; 2006).

\section{A fenomenologia e a pesquisa qualitativa}

A fenomenologia foi um dos movimentos filosóficos que, desde sua constituição, guardou relações de grande proximidade e interesse pela recém-criada psicologia (Dartigues, 2003; Forghieri, 1993; Holanda, 2002; Husserl, 1965; 1985; 1992; Moreira, 2002; Spiegelberg, 1972).

No contexto das discussões sobre a queda dos grandes sistemas filosóficos tradicionais na época (Dartigues, 2003), a fenomenologia buscou preencher o espaço deixado vazio pela filosofia especulativa, baseando-se nas ideias de Franz Brentano, que já propunha a especificidade da conduta humana como fonte da subjetivação (Holanda, 2002; Maciel, 2003; Ramón, 2006). A perspectiva de Husserl ultrapassa a psicologia descritiva de Brentano quando, ao analisar a doutrina da intencionalidade, parte para sua investigação "na vivência de consciência como tal, e chega a uma análise profunda do conhecimento que ultrapassa os limites da Psicologia" (Forghieri, 1993, p.14).

Petrelli (2004) explicita que a fenomenologia éa ciência que se aplica ao estudo dos fenômenos: dos objetos, dos eventos e dos fatos da realidade. De acordo com o autor, ela oferece "uma verdade, em partes e em momentos, e nunca na sua transparência total, pois é a dúvida, e não a certeza, que nos motiva à busca incessante da verdade" (p.12). Faz-se necessário lembrar que "a verdade é um movimento em constituição, não um estado" (Moreira, 2004, p.449). A fenomenologia busca o retorno aos dados primordiais da experiência (Dartigues, 2003; Moustakas, 1994). Uma vez que os fenômenos são sempre anteriores às teorias e aos conceitos, o que é dado na percepção de uma coisa é sua aparência e as aparências são sempre aparência de alguma coisa. Conclui-se, portanto, que os fenômenos são primários e têm natureza própria.

Qualquer ciência que descreva aparências ou aparições faz fenomenologia (Abbagnano, 2003; Dartigues, 2003). De acordo com Cappi (2004, p.8), a fenomenologia"é um rigoroso olhar metodológico a respeito do real, é uma opção radical de percepção" a fim de desvelar significados, criar valores e assumir responsabilidades. Tudo que se oferece ao conhecimento humano pode ser chamado de realidade fenomênica. Com base nesses pressupostos, Merleau-Ponty (1999) define a fenomenologia como o estudo das essências e acrescenta que ela é uma filosofia que recoloca as essências na existência, reconstituindo a relação entre homem e mundo. Éainda uma"filosofia transcendental que coloca em suspenso, para compreendê-las, as afirmações da atitude natural" (p.1).

Convém discutirmos alguns conceitos fundamentais da fenomenologia para uma melhor compreensão do método fenomenológico na pesquisa.

\section{O retorno às coisas mesmas e a intencionalidade}

A fenomenologia busca o conhecimento das essências. Para alcançar tal objetivo, Husserl (1965) pro- 
põe retornar a um ponto de partida que seja, verdadeiramente, o primeiro, ou seja, um retorno às origens, à coisa mesma, tendo como dado a própria realidade. A máxima da fenomenologia de ir às coisas mesmas provoca uma nova experiência e um novo conhecimento.

Segundo Merleau-Ponty (1999), retornar às coisas mesmas é retornar ao mundo tal qual ele surge, anteriormente à consciência. Husserl (1992) assinala que a relação entre consciência e mundo é sempre intencional, havendo entre ambos uma correlação essencial. A consciência intencional possibilita que o mundo apareça como fenômeno, como significação, evidenciando que a saída de si para um mundo tem uma significação para ele (Bicudo, 2000; Dartigues, 2003; Forghieri, 1993; Holanda, 2002; Martins \& Bicudo, 2005; Merleau-Ponty, 1999).

Nessa perspectiva, Giorgi (1978) faz uma reflexão sobre o que é consciência para o pesquisador na tradição fenomenológica; ele indica, inicialmente, que a consciência deva ser considerada sempre associada, em geral, aos conceitos de intencionalidade, sentido e existência, e define o termo consciência indo além da relação cognitiva de sujeito e objeto, como uma relação existencial do sujeito com o seu mundo, sendo "existência" o modo pelo qual o sujeito se posiciona diante da vida. A exploração do campo de consciência e dos modos de relação com o objeto delimita o que se tornará o campo de análise da fenomenologia de Husserl.

\section{A redução fenomenológica e a intuição das essências}

A redução é o recurso usado pela fenomenologia para chegar à essência do fenômeno, tornando-o compreensível e legitimando-o cientificamente. O primeiro passo para que isso aconteça é a mudança da "atitude natural" para a "atitude fenomenológica". Como explicita Forghieri (1993), essa mudança de atitude permite visualizar o mundo do sujeito como fenômeno "ou como constituinte de uma totalidade, no seio da qual o mundo e o sujeito revelam-se, reciprocamente, como significações" (p.15). O pesquisador somente alcança o fenômeno em si se consegue pôr fora de circuito o conhecimento do mundo (Husserl, 1985).

Nessa perspectiva, o pesquisador fenomenólogo

262 coloca-se em posição orientada para a descoberta, ou seja, põe-se aberto para qualquer tipo de conteúdo ou tema que venha a emergir na sua pesquisa. Em decorrência disso, é comum a pesquisa fenomenológica alcançar resultados novos, totalmente imprevistos, pois está aberta ao novo e às possibilidades criativas de compreensão do objeto de estudo.

A redução fenomenológica consiste, então, "numa profunda reflexão que nos revele os preconceitos em nós estabelecidos e nos leve a transformar este condicionamento consciente, sem jamais negar a sua existência" (Merleau-Ponty, 1973, p.22). No entanto Merleau-Ponty (1999) esclarece: "O maior ensinamento da redução é a impossibilidade de uma redução completa" (p.10). Como na redução, que nunca se completa, o pesquisador também não consegue, no absoluto, deixar de lado suas hipóteses ao pesquisar o fenômeno. Como assinala Moreira (2004), nos resultados, o pesquisador sai do parêntese e volta a olhar para a sua hipótese, assume-se integralmente como pesquisador mundano, dialogando com os resultados da pesquisa e, sobretudo, posicionando-se diante dos resultados.

De forma semelhante, Forghieri (1993) faz uma reflexão importante sobre a redução fenomenológica no campo da psicologia ao propor dois momentos inter-relacionados e reversíveis da redução: o envolvimento existencial e o distanciamento reflexivo. A autora sintetiza que a redução "inicia-se com o retorno do pesquisador à vivência e sua penetração na mesma; prossegue com o distanciamento reflexivo que consiste na reflexão sobre a vivência e na enunciação de seu significado para a pessoa que a experiência" (p.60).

Com base na redução fenomenológica, Husserl (2000) orienta sua pesquisa para as essências, pois a fenomenologia tem como tarefa elucidar as essências. É pela redução fenomenológica que se chega às essências invariantes, constitutivas da realidade. Petrelli (2004) resgata que a redução fenomenológica é "conduzida pela consciência com um instrumento que Husserl indica com o termo de 'intencionalidade', caracterizando, assim, a essência da própria consciência" (p.19).

Husserl (2000) aponta que as essências representam as unidades básicas do entendimento comum de qualquer fenômeno, aquilo sem o qual o próprio fenômeno não pode ser concebido. Essência é aquilo 
que é inerente ao fenômeno. A intuição da essência é"a visão do sentido ideal que atribuímos ao fato materialmente percebido e que nos permite identificá-lo" (Dartigues, 2003, p.15). A essência permite identificar o fenômeno.

Merleau-Ponty (1999) dá um passo adiante ao esclarecer que a fenomenologia busca as essências na existência, visto que o mundo está sempre aí, antes da reflexão. Não se pode pensar a essência desvinculada do mundo.

Em virtude da constante busca de vinculação entre essência e mundo, Creswell (1998) mostra que é tarefa dos pesquisadores buscar a essência da experiência e enfatizar a intencionalidade da consciência. A análise fenomenológica dos dados realiza-se por intermédio da metodologia da redução, da análise de afirmações e temas específicos e da busca de todos os significados possíveis. Para tanto, o pesquisador deve suspender seus a priori e se apoiar no que surgirá da experiência pesquisador-pesquisado.

\section{O mundo-da-vida}

método fenomenológico é a descrição das experiências vividas pelos sujeitos pesquisados sobre um determinado fenômeno com o objetivo de buscar sua estrutura essencial (Creswell, 1998). E todo o universo da ciência está construído sobre o mundo-da-vida - o Lebenswelt, na denominação husserliana -, sendo a ciência uma expressão segunda, ao passo que a experiência do mundo é a sua expressão primeira.

Gadamer (1998) retrata o conceito fenomenológico de mundo-da-vida, desenvolvido por Husserl, como aquele em que o homem adentra simplesmente por viver a atitude natural e que significa o solo prévio de toda experiência. O mundo-da-vida é mais originário que a ciência, estando essencialmente vinculado à subjetividade. É um conceito que se deixa formular com sentido na experiência histórica, pois parte da vasta progressão dos mundos humano-históricos, e não de um mundo queé. O mundo-da-vidaé, enfim, a totalidade em que o homem vive como ser histórico, é um mundo pessoal que se fundamenta na copresença de outros mundos.

Para Martins e Bicudo (2005), a pesquisa fenomenológica está relacionada diretamente à ideia do mundo-da-vida, que é o mundo do pré-reflexivo. Os autores confirmam que o sustentáculo de qualquer relação de vivido é o estar-no-mundo, sendo o mundo em que se está, esse mundo real, o mundo do pré-reflexivo.

A experiência do vivido somente pode ser alcançada pelo próprio sujeito de forma imediata, pois o sentido é particular para quem o vive e está ligado à forma da pessoa existir no mundo (Forghieri, 1993). Esse é o motivo pelo qual o mundo-da-vida precisa ser percebido e descrito em vez de ser interpretado ou julgado. A descrição possibilita resgatar o vivido com base no retorno da sua percepção ao momento imediato. 0 vivido, uma vez vivido, somente retorna pela memória - por meio de uma ressignificação ou resgate -, que é viver novamente no presente (Holanda, 2002; 2003a; 2003b).

O mundo vivido, portanto, propicia ao pesquisador ir além do conteúdo meramente intelectual e alcançar o conteúdo afetivo-emocional, que é específico para uma determinada pessoa ou grupo. Amatuzzi (2006) esclarece, nesse ponto, a diferença entre a ciência que se refere a um conhecimento objetivo - cercada de todas as garantias de segurança e isenta de qualquer subjetividade - e a que intenciona a consciência da experiência, que é o conhecimento de um saber. Na ciência, todo o campo de conhecimento é preenchido pelo objeto; na consciência, é enfatizada a relação pesquisador-pesquisado, ambos presentes no campo e capazes de alterá-lo. A fenomenologia administra o em-si e o para-si da relação sujeito-objeto e o para-outrem.

Gomes (1997) ressalta que a pesquisa fenomenológica estuda a vivência como experiência consciente. $\mathrm{O}$ autor constata que a experiência consciente do mundo vivido se esclarece tendo em vista a significação dos acontecimentos que a constituem, pois contém os entrelaçamentos inextrincáveis do eu com o outro e com o mundo. "A experiência consciente é um ato comunicativo de um corpo situado em um determinado ambiente. A mensagem que expressa traz a peculiaridade de um mundo vivido", declara Gomes (1997, p.320).

\section{O método fenomenológico em pesquisa}

Amatuzzi (1996) afirma que a pesquisa fenomenológica é uma forma de pesquisa qualitativa que "designa o estudo do vivido, ou da experiência imediata pré-reflexiva, visando descrever seu significado; ou 
qualquer estudo que tome o vivido como pista ou método. É a pesquisa que lida, portanto, com o significado da vivência" (p.5).

O método fenomenológico, segundo Holanda (2002; 2003b), deve buscar acessar a essência do fenômeno estudado, o que pode ser alcançado a partir dos três elementos fundamentais da fenomenologia. 0 primeiro elemento é a redução fenomenológica, que possibilita acessar a verdade do sujeito. O segundo elemento é a intersubjetividade, que é a relação estabelecida entre o sujeito-pesquisador e o sujeito-pesquisado - duas histórias próprias que se encontram para compreender um fenômeno. O terceiro elemento é o retorno ao vivido, no qual o sujeito-pesquisado retoma sua história.

O interesse das investigações é captar o mundo vivido que não é, necessariamente, sabido de antemão, mas que no ato da relação pessoal, dada a oportunidade de expressão, é acessado (Amatuzzi, 2003).

O método fenomenológico apresenta-se à psicologia como um recurso apropriado para pesquisar o mundo vivido do sujeito com a finalidade de investigar o sentido ou o significado da vivência para a pessoa em determinada situação, com o intuito de buscar a estrutura essencial ou invariante do fenômeno. Segundo Amatuzzi (2003), o método fenomenológico pretende apreender o que acontece por meio do clareamento do fenômeno, construindo, assim, a compreensão de algo.

O pensamento fenomenológico, entretanto, enfrenta muitas dificuldades em sua comunicação e interpretação. Uma delas é que, ao longo da obra de Husserl (1965; 1985; 1992; 2000), as ideias foram evoluindo e ganhando novos contornos. Um segundo problema está no fato de podermos delimitar diversos modos de pensar a fenomenologia ou, até mesmo, segundo alguns autores (Giorgi, 1985; 2006; Holanda, 2002), falar de diversas "fenomenologias" com ênfases específicas. Para isso, basta notarmos que, historicamente, vários grupos foram se formando ao redor de Husserl e alguns desses grupos ganharam independência do mentor, como foi o caso do grupo de Göttingen, que não seguiu a linha do idealismo transcendental das Ideen ou mesmo do desenvolvimento de filosofias autônomas, como encontramos em Scheler ou Merleau-Ponty (Giorgi, 1985, 2006; Holanda, 2002; Mohanty, 1996; Morujão, 1990).

Creswell (1998) segue uma trajetória semelhante ao afirmar que o uso do método fenomenológico pode

264 ser desafiador. Além de o pesquisador precisar de uma consistente base - no tocante aos princípios filosóficos da fenomenologia -, os colaboradores no estudo necessitam ser cuidadosamente escolhidos por serem indivíduos que experienciam o fenômeno. Outro desafio é o pesquisador suspender as experiências pessoais, um objetivo sempre presente e nunca alcançado em sua plenitude. Um quarto desafio é a decisão sobre a forma como suas experiências pessoais serão introduzidas no estudo.

Ao mesmo tempo em que o método fenomenológico enfrenta dificuldades e desafios, ele propicia um caminho coerente e sólido tão importante na pesquisa em psicologia. Martins e Bicudo (2005) referem-se ao método fenomenológico como uma descrição exaustiva do fenômeno. Pode-se comparar o trabalho do fenomenólogo ao de um jornalista que investiga a natureza de um fenômeno, interrogando-o (Martins \& Bicudo, 2005).

A premissa que consiste em interrogar o fenômeno como se ele estivesse sendo observado pela primeira vez direciona a maneira pela qual o pesquisador irá inserir-se na pesquisa. Para chegar à experiência vivida do sujeito, é necessário que o pesquisador procure colocar "entre parênteses" os conhecimentos adquiridos anteriormente sobre o objeto investigado. É por isso que o método fenomenológico não prescinde das hipóteses; embora a pesquisa necessite ter uma direção, ela não se deixa conduzir por um caminho já conhecido, pois se trata de direções rígidas e previamente fixadas.

A tentação do pesquisador de dirigir suas análises com bases em hipóteses rígidas pode levá-lo ao grande perigo de a pesquisa não produzir nenhum conhecimento significativo. As metas pré-fixadas e as expectativas do pesquisador podem direcionar o andamento da pesquisa (González Rey, 2005; Petrelli, 2004). Qual pesquisador não se sente gratificado quando, ao final da pesquisa, os resultados confirmam as hipóteses, mesmo que suspensas? Na concepção de Petrelli (2004), o método fenomenológico não rejeita hipóteses, mas as suspende num primeiro momento e as recupera a posteriori, numa postura dialética.

A suspensão dos conceitos é o primeiro momento do processo. Essa redução chamada teorética consiste em eliminar qualquer construto conceitual, ou seja, reter o saber acumulado (Petrelli, 2004). A redução teorética é necessária, pois a fenomenologia deve garantir à ciência sua própria pureza ao buscar a dimensão ética, não manipuladora da realidade. 
Um dos recursos amplamente utilizados para alcançar a compreensão do fenômeno, da realidade estudada, é a entrevista, na qual o pesquisador pode explorar a experiência vivida e o sentido que o mundo vivido tem para o entrevistado ou entrevistados, e perceber como diferentes sujeitos experienciam certa condição comum a eles.

Os sujeitos são chamados por Amatuzzi (2003) de colaboradores, pois o autor entende que a pesquisa fenomenológica não lida com sujeitos que forneçam informações, mas colaboradores que, juntos, tratam do assunto. Parte-se do pressuposto metodológico de que o colaborador é quem melhor sabe de sua experiência, ao passo que o pesquisador se propõe a aprender com quem já vivenciou ou vivencia a experiência sobre a qual ele quer aprimorar seus conhecimentos (Moreira, 2004). Nessa troca, ambos saem transformados.

O comprometimento de ambas as partes, segundo González Rey (2005), é fundamental para alcançar o objetivo da pesquisa, mas algumas dificuldades podem surgir: o medo de a pessoa entrar em contato com feridas ainda abertas, o temor de conversar sobre intimidades, o confronto de seus valores, a não confiança no pesquisador, o desinteresse pela pesquisa, dentre outros. Qualquer impasse na entrevista precisa ser esclarecido para que o processo de conhecimento continue, sob pena de se perderem o compromisso e a cumplicidade.

O método fenomenológico de pesquisa em psicologia é apresentado no singular, apesar de ele não se constituir de um só modelo e de haver aspectos que são comuns a qualquer método fenomenológico. Moreira (2004), no entanto, destaca que existem características e nuanças específicas da fenomenologia de cada uma das grandes vertentes desse movimento. Essas diferenças advêm da sua própria diversidade.

Por existirem várias e não uma única forma de apreensão da fenomenologia (como se pode exemplificar, na Filosofia, por intermédio dos pensamentos de Sartre, Merleau-Ponty, Scheler e outros), a metodologia fenomenológica de pesquisa em psicologia sofre variações de acordo com o pensamento filosófico que a sustenta, apesar de todas terem um eixo comum: a busca do significado da experiência. Neste estudo, a fenomenologia tem sido abordada de acordo com os fundamentos de Edmund Husserl e alguns seguidores.

Gomes (1997), um dos grandes estudiosos brasileiros da fenomenologia, faz uma breve exposição do método fenomenológico e revela que se baseou em estudos de Kockelmans e de Husserl. Para o uso do método fenomenológico, Gomes (1997) estabelece três passos reflexivos que permitem o estudo da experiência consciente por meio do estudo e transcrição de entrevistas: descrição fenomenológica, redução fenomenológica e interpretação fenomenológica.

O primeiro passo do método fenomenológico de Gomes (1997) sugere a descrição do objeto da experiência com base no material empírico colhido na entrevista. A descrição deve ser feita como se o pesquisador tivesse acesso ao fenômeno pela primeira vez. Para tanto, suspende-se o que já é conhecido pelo pesquisador e interroga-se o objeto como se absolutamente nada se soubesse a seu respeito. No entanto, da mesma forma que não é possível colocar a experiência entre parênteses por completo, a descrição também não é completa (Dias \& Gomes, 1999; Gomes, 1997; Merleau-Ponty, 1999).

Concluída a descrição, passa-se ao segundo passo: a exploração exaustiva do material descrito. É um retorno à descrição para questioná-la, especificando suas partes temáticas, evidenciando o que é essencial à identificação do objeto. Uma vez identificado o essencial, retorna-se às entrevistas para localizar novos subsídios que confirmem, ou não, a relevância da parte escolhida. Conclui-se o segundo passo com a preparação de uma nova descrição, que acaba sendo uma nova consciência do objeto da experiência. Nessa fase, define-se o objeto e fazem-se as distinções entre o essencial e o não essencial (Dias \& Gomes, 1999; Gomes, 1997).

No terceiro passo, revela-se a intencionalidade da consciência para aquele determinado objeto da experiência, ou seja, o sentido que aquele objeto assume para a consciência. Husserl procurava nesse último passo do seu método um eu submerso na experiência. A inves-tigação chega ao fim com o reconhecimento da inten-cionalidade do outro. A interpretação caracteriza-se como indicação de possibilidades e não como gene-ralização de achados do fenômeno investigado (Dias \& Gomes, 1999; Gomes, 1997).

Cada passo inclui os demais. Gomes (1997) exemplifica essa afirmação ao esclarecer: "a redação da descrição, primeira etapa do método, é composta da redução e da interpretação porque envolveu necessariamente escolhas do pesquisador" (p. 328). O autor, de forma muito clara, resume as etapas do método fenomenológico: 
Inicialmente, têm-se os dados brutos constituídos pelos protocolos de entrevista. Neste momento, este conjunto de protocolos funciona como uma descrição bruta. A tarefa de questionamento destes protocolos e a organização deste material em unidades compreensivas é, então, a redução. A redação de um texto final é a interpretação (p.328).

Para Gomes (1997), esses três passos são tecnicamente realizados com as entrevistas, as transcrições, as definições de unidades mínimas de sentido, a elaboração de sínteses descritivas de cada entrevista e a definição das grandes categorias, passos semelhantes aos descritos por Giorgi (1985).

Petrelli (2004) sugere um quarto passo ou momento desse itinerário investigativo, quando o pesquisador articula os dados relativos ao fenômeno em estudo, os dados da eidética universal e os da eidética individualizante e determinante do objeto. Nesse momento, o fenomenólogo compara o novo conhecimento com os conhecimentos antecedentes concomitantes. Teorias caem, teorias mantêm-se e novas teorias podem surgir. Forghieri (1993) assinala que "os cientistas em geral almejam com suas investigações conseguir captar e enunciar o verdadeiro significado da realidade" (p.57).

Apresentaremos sucintamente a perspectiva de Giorgi (1985), que tem sido muito utilizada por pesquisadores qualitativos e que proporciona uma sistemática transparente de trabalho, pois sua proposta indica e contextualiza as escolhas do pesquisador. Na psicologia, Amedeo Giorgi tem sido considerado um importante representante do método fenomenológico (Gomes, 1997; Holanda, 2002; Moreira, 2002).

\section{Um modelo fenomenológico: Amedeo Giorgi}

Amedeo Giorgi coordenou, durante muito tempo, na University of Duquesne, um grupo de pesquisas de orientação fenomenológica e elaborou passos bem detalhados para um trabalho fenomenológico. Seu modelo é comumente descrito como uma fenomenologia empírica ou fenomenologia experimental, e constitui o desdobramento dos estudos pioneiros de Adrian Van Kaam, na década de 1950, com a "pesquisa empírico-fenomenológica" (Amatuzzi, 1996; Gomes, 1998; Holanda, 2002; 2003a; Moustakas, 1994).

O modelo da "fenomenologia empírica" em psicologia costuma estar associado ao pioneirismo de Adrian van Kaam, a partir de seu trabalho intitulado
Phenomenal Analysis: Exemplified by a Study of the Experience of 'Really Feeling Understood', publicado em 1959 (van Kaam, 1959). Posteriormente, outros pesquisadores depuraram esse modelo, desenvolvendo novas perspectivas, como encontramos em Colaizzi (1978), Sanders (1982) ou Davidson (1992). Todavia quem melhor elaborou esse modelo foi Amedeo Giorgi.

A proposta de Giorgi (1985) lida com as descrições de depoimentos, relatos ou entrevistas sobre experiências vividas em relação a um determinado fenômeno segundo quatro passos, que serão discutidos a seguir.

O sentido do todo, primeiro passo apresentado por Giorgi (1985), corresponde à leitura de toda a descrição a fim de alcançar o sentido geral do todo. Para tanto, é necessário compreender a linguagem de quem descreve sem qualquer tentativa de identificar as unidades significativas. O senso geral obtido é a base para o passo seguinte.

O segundo passo é a discriminação de unidades significativas com base em uma perspectiva psicológica e focada no fenômeno que é pesquisado. Após ter sido apreendido o sentido do todo, o pesquisador faz a releitura do texto - tantas vezes quanto necessárias - com o objetivo de discriminar as unidades significativas na perspectiva psicológica, focalizando o fenômeno que está sendo pesquisado. Esse passo é necessário, pois não se pode analisar um texto inteiro simultaneamente, devendo-se quebrá-lo em unidades significativas, que emergem sempre que se percebe uma mudança psicologicamente sensível de significado da situação para o sujeito. As discriminações são espontaneamente percebidas dentre as descrições do sujeito e são alcançadas quando o pesquisador assume uma atitude psicológica em relação à descrição concreta. Nesse passo, a linguagem do sujeito quase não é mudada. É essencial para o método que as discriminações ocorram primeiro para serem interrogadas mais adiante - no próximo passo -, e que elas sejam feitas espontaneamente, mesmo sendo uma espontaneidade disciplinada.

As unidades de significado não existem soltas, mas em relação à perspectiva adotada pelo pesquisador (Holanda, 2002). Essas unidades são constitutivas do texto e não apenas elementos isolados. A realidade psicológica não está pronta no mundo, ela precisa ser constituída pelo psicólogo, sempre lembrando que o mundo cotidiano é mais rico e mais complexo do que a perspectiva psicológica, tanto que vários pesquisadores podem analisar de maneira diferente o mesmo conjunto de dados. 
O contexto da descoberta da pesquisa é constituído na relação. Assim, as unidades significativas não existem no texto como tais, mas apenas em relação a atitudes e cenários do pesquisador, e, por esse motivo, o que se destaca depende muito da perspectiva do pesquisador.

O terceiro passo é configurado pela transformação das expressões cotidianas do sujeito em linguagem psicológica com ênfase no fenômeno que está sendo investigado. Uma vez que as unidades significativas foram delineadas, o pesquisador, então, passa por todas elas e expressa o sentido psicológico nelas contido. É a transformação da linguagem do dia a dia do sujeito em linguagem psicológica apropriada, com ênfase no fenômeno em estudo.

É possível alcançar esse objetivo por meio de uma ampla interrogação do texto, com o intuito de verificar o que exatamente o narrador quis expressar com seus termos. Giorgi (1985) alerta que o maior obstáculo para esse processo é ainda não existir uma linguagem psicológica consensual estabelecida. Diante dessa dispersão, a melhor alternativa é usar a linguagem do senso comum, esclarecida pela perspectiva fenomenológica. Esse passo tem o propósito de chegar às categorias, passando por expressões concretas.

O último passo do método fenomenológico apresentado por Giorgi (1985) busca a sintese das unidades significativas transformadas em uma declaração consistente da estrutura do aprendizado. Finalmente, o pesquisador propõe que se sintetizem todas as unidades significativas transformadas em uma declaração consistente da significação psicológica dos fenômenos observados em relação à experiência do sujeito e denomina essa síntese de estrutura da experiência.

Para realizar tal tarefa, o pesquisador deve reagrupar os constitutivos relevantes para chegar a uma análise da estrutura do fenômeno. Todas as unidades de significado transformadas devem ser consideradas. $\bigcirc$ critério aconselhável a ser seguido é o de que todas as unidades transformadas estejam, pelo menos implicitamente, contidas na descrição geral. A estrutura da experiência deve, então, ser comunicada a outros pesquisadores com o propósito de confirmação ou de crítica.

O modelo de Giorgi expressa muito bem as possibilidades que o método fenomenológico tem de acesso ao mundo vivido. Pretende-se, com isso, apontar para o fato de que a fenomenologia, como fundamento teórico e metodológico, mostra-se um modelo adequado às ciências humanas, sociais e da saúde quando elas tomam o sujeito em seu contexto de vivência e o homem como protagonista.

\section{Considerações Finais}

Um dos objetivos desse trabalho foi apresentar o modelo de pesquisa qualitativa como possibilidade de acesso e leitura científica da realidade psicológica. Dentro dessa perspectiva, o modelo empírico-fenomenológico surge como uma alternativa viável por aliar a objetividade na coleta e análise de dados à apreensão da realidade subjetiva tanto da parte do pesquisador quanto da do colaborador.

A pesquisa qualitativa vem sendo cada vez mais utilizada no contexto acadêmico e representa o resgate dos processos de subjetivação no âmbito da ciência. No esteio das propostas de constituição das "ciências do espírito", o desenvolvimento das modernas ciências humanas e sociais - que incluem, fundamentalmente, a antropologia, a sociologia e a psicologia - demanda sucessivas revisões de seus campos epistemológicos e igualmente de suas estruturações de pesquisa, compatíveis com os modos de subjetivação. Nesse contexto se enquadra o modo de se fazer pesquisa dito "qualitativo", e, no processo de construção desses novos modos de pesquisa - a realidade subjetiva -, a proposta da fenomenologia surge como uma excepcional perspectiva de olhar o fenômeno humano no sentido da descoberta e desvelamento desse particular fenômeno da realidade.

\section{Referências}

Abbagnano, N. (2003). Dicionário de filosofia. São Paulo: Martins Fontes.

Amatuzzi, M. M. (1996). Apontamentos acerca da pesquisa fenomenológica. Estudos de Psicologia (Campinas), 13 (1), 5-10.

Amatuzzi, M. M. (2003). Pesquisa fenomenológica em Psicologia. In M. A. Toledo Bruns \& A. F. Holanda (Orgs.), Psicologia e fenomenologia: reflexões e perspectivas (pp.17-16). Campinas: Alínea.

Amatuzzi, M. M. (2006). A subjetividade e sua pesquisa. Memorandum, 10, 93-97.

Bicudo, M. A. (2000). Fenomenologia: confrontos e avanços. São Paulo: Cortez.

Bruns, M. A. T., \& Holanda, A. F. (2003) (Orgs.), Psicologia e fenomenologia: reflexões e perspectivas. Campinas: Alínea. 
Buber, M. (1965). Between man and man. New York: MacMillan Paperbacks.

Buber, M. (1979). Eu e tu. São Paulo: Moraes.

Buber, M. (1982). Do diálogo e do dialógico. São Paulo: Perspectiva.

Cappi, A. (2004). Apresentação. In R. Petrelli. Fenomenologia: teoria, método e prática (pp.7-8). Goiânia: Editora UCG.

Colaizzi, P. F. (1978). Psychological research as the phenomenologist views it. In R. S. Valle \& M. King (Eds.), Existential phenomenological alternatives for psychology (pp.48-71). New York: Oxford University Press.

Creswell, J. (1998). Qualitative inquiry and research design: choosing among five traditions. Thousand Oaks: Sage.

Dartigues, A. (2003). O que é a fenomenologia? São Paulo: Centauro.

Davidson,L.(1992).Developinganempirical-phenomenological approach to schizophrenia research. Journal of Phenomenological Psychology, 23 (1), 3-15.

Dias, A. C., \& Gomes, W. (1999). Conversas sobre sexualidade na família e gravidez na adolescência: a percepção dos pais. Estudos de Psicologia (Natal), 4 (1), 79-106.

Forghieri, Y. (1993). Psicologia fenomenológica. São Paulo: Pioneira

Gadamer, H-G. (1998). Verdade e método. Petrópolis: Vozes.

Giorgi, A. (1978). Psicologia como ciência humana: uma abordagem de base fenomenológica. Belo Horizonte: Interlivros.

Giorgi, A. (1985). Sketch of a psychological phenomenological method. In A. Giorgi (Org.), Phenomenology and psychological research (pp.8-22). Pittsburg: Duquesne University Press.

Giorgi, A. (2006). Difficulties encountered in the application of the phenomenological method in the social sciences. Análise Psicológica, 24 (3), 353-361. Recuperado em agosto 20, 2007, disponível em http://www.scielo.oces. mctes.pt/scielo.php?script=sci_arttext\&pid=S0870-82 312006000300009\&lng=pt\&nrm $=$ iso

Gomes, W. (1997). A entrevista fenomenológica e o estudo da experiência consciente. Psicologia USP, 8 (2), 305-336.

Gomes, W. (1998). Fenomenologia e pesquisa em psicologia. Porto Alegre: UFRGS.

González Rey, F. (2002). Pesquisa qualitativa em psicologia: caminhos e desafios. São Paulo: Pioneira.

González Rey, F. (2003). Epistemología cualitativay subjetividad. São Paulo: Educ.

González Rey, F. (2005). Pesquisa qualitativa e subjetividade. São Paulo: Thomson.

Holanda, A. (2002). O resgate da fenomenologia de Husserl e a pesquisa em psicologia. Tese de doutorado não-publicada, Pontifícia Universidade Católica de Campinas.

Holanda, A. (2003a). Fundamentação fenomenológica da pesquisa no vivido. In I. Costa, A. F. Holanda, F. Martins \& M. I. Tafuri (Orgs.), Ética, linguagem e sofrimento (pp.171-183). Brasília: Abrafipp.

Holanda, A. (2003b). Pesquisa fenomenológica e psicologia 268 eidética: elementos para um entendimento metodo- lógico. In M. A. Toledo Bruns.\& A. F. Holanda (Orgs.), Psicologia e fenomenologia: reflexões e perspectivas (pp.35-56). Campinas: Alínea.

Holanda, A. (2006). Questões sobre pesquisa qualitativa e pesquisa fenomenológica. Análise Psicológica, 24 (3), 363-372.

Husserl, E. (1965). A filosofia como ciência de rigor. Coimbra: Atlântida.

Husserl, E. (1985). Idées directrices pour une phénoménologie et une philosophie phénoménologique pures. Paris: Gallimard.

Husserl, E. (1992). Conferências de Paris. Lisboa: Edições 70.

Husserl, E. (2000). A idéia da fenomenologia. Lisboa: Edições 70.

Maciel, J. C (2003). Franz Clemens Brentano e a psicologia. In A. F. Holanda \& M. A. T. Bruns (Orgs.), Psicologia e fenomenologia: reflexões e perspectivas (pp.27-39). Campinas: Alínea.

Martins, J., \& Bicudo, M. (2005). A pesquisa qualitativa em psicologia. São Paulo: Centauro.

Merleau-Ponty, M. (1973). Ciências do homemefenomenologia. São Paulo: Saraiva.

Merleau-Ponty, M. (1999). Fenomenologia da percepção. São Paulo: Martins Fontes.

Mohanty, J. N. (1996). The development of Husserl's thought. In B. Smith \& D. W. Smith. The Cambridge companion to Husserl (pp.45-77). Cambridge: Cambridge University Press.

Moreira, D. A. (2002). O método fenomenológico na pesquisa. São Paulo: Pioneira-Thonson.

Moreira, V. (2004). O método fenomenológico de MerleauPonty como ferramenta crítica na pesquisa em psicopatologia. Psicologia: Reflexão e Crítica, 17 (3), 447-456.

Morujão, A. F. (1990). Escola fenomenológica. In Logos: - enciclopédia luso-brasileira de filosofia. Lisboa: Verbo.

Moustakas, C. (1994). Phenomenological research methods. Thousand Oaks: Sage Publications.

Petrelli, R. (2004). Fenomenologia: teoria, método e prática. Goiânia: UCG.

Ramón, S. P. (2006). A importância da act-psychology de Franz Brentano. Psicología, Reflexão e Crítica 19 (2), 340-345, Retrieve in Aug 19, 2007, available from http:// www.scielo.br/scielo.php?script=sci_arttext\&pid=S0 102-79722006000200021\&lng=pt\&nrm=iso

Sanders, P. (1982). Phenomenology: a new way of viewing organizational research. Academy of Management Review, 7 (3), 353-360.

Spiegelberg, H. (1972). Phenomenology in Psychology and Psychiatry: a historical introduction. Evanston: Northwestern University Press.

van Kaam, A. L. (1959). Phenomenal analysis: exemplified by a study of the experience of 'really feeling understood'. Journal of Individual Psychology, 15 (1), 66-72.

Recebido em 4/12/2007

Versão final reapresentada em 31/10/2008

Aprovado em: 27/11/2008 